\section{EMBRYRIDDLE}

Aeronautical University

SCHOLARLY COMMONS
Journal of Aviation/Aerospace Education \& Research

Volume 7

Number 2 JAAER Winter 1997

Article 1

Winter 1996

\title{
Aviation English: An Introduction
}

Peter H. Ragan

Follow this and additional works at: https://commons.erau.edu/jaaer

\section{Scholarly Commons Citation}

Ragan, P. H. (1996). Aviation English: An Introduction. Journal of Aviation/Aerospace Education \& Research, 7(2). https://doi.org/10.15394/jaaer.1997.1189

This Article is brought to you for free and open access by the Journals at Scholarly Commons. It has been accepted for inclusion in Journal of Aviation/Aerospace Education \& Research by an authorized administrator of Scholarly Commons. For more information, please contact commons@erau.edu. 


\title{
AVATION ENGLISH: AN INTRODUCTION
}

\author{
Peter H. Ragan
}

Aviation is a specialized, technology-based area that covers a broad range of activities, from esoteric analyses of compressible fluids, to selling tickets, to getting a clearance for takeoff. Accordingly, the language behavior inherent to such activities is diverse, often requiring specialized uses of English that are collectively labeled here as Aviation English. Aviation English figures prominently in most fields of aviation/aerospace education and practice, in regulatory and administrative agencies concerned with national and international commerce, norms and standards, and in academic, industrial, and government research and development. A greater awareness of the nature of Aviation English and of relevant resources can assist those aviation professionals whose daily work depends significantly on the use of language. Toward this end, this paper has been written for the aviation professional, not the language specialist. It serves as a general introduction to Aviation English by presenting background for the need to address this issue of language, describing the nature of aviation uses of language, reviewing selected, pertinent writings on the subject, and concluding with ideas for advancing our knowledge and refining our use of Aviation English.

\section{BACKGROUND}

The creation of cockpit resource management and quality assurance programs and of in-house safety departments in the airline industry recognizes the complexity of commercial aviation operations. As industry becomes more aware of the interrelation of the components of this complexity, it is no surprise that language use has come under scrutiny as well. In 1995, driven by concerns with flight safety, U.S. Transportation Secretary Federico Pena, among others, urged consideration of English language proficiency tests for commercial pilots and the establishment of an improved lexicon of standard aviation terms used by pilots and air traffic controllers ("Pena to Airlines," 1995). In the preamble to its "Notice of Proposed Rulemaking" (1995), the Federal Aviation Agency has proposed to standardize English language fluency requirements for all FAA certificates and ratings because it is concerned about the safety hazard caused by pilots' inability to communicate sufficiently by radio and to deal adequately with air traffic control.

Aviation professionals' need for safety and efficiency in communication has led to creative combinations of technology, automation, and language -- witness the FAA's DATALINK, a computerized communication device in which menu-driven communication choices can be electronically exchanged between aircraft and control tower computers. Computerized database and expert systems for speech recognition and natural language understanding await the refinement of speech recognizers for application in simulated and real aviation environments.

The concern with language in general, and with English in particular, is well-founded and implicitly acknowledges aviation as an international phenomenon. However, although English is the international language of the air, it is not the primary language of all those who are using it. Indeed, levels of English proficiency among aviation professionals vary tremendously around the world. With continuing immigration and the relocation of significant refugee populations, it is no longer possible to assume a common language background among the inhabitants of any given country, including those in which English has commonly been considered the first language.

Political change and needs have indeed affected the use of English in the aviation profession around the world. The proliferation of new countries resulting from the breakup of the Soviet Union and the development of the aviation industry in China are just two examples that draw attention to the need for language training and international cooperation regarding acceptable standards 
of English as the lingua franca of aviation. Here in the United States, growing numbers of local and international students with limited English proficiency (LEP) are participating in flight programs and aviationrelated training in preparation for entry into the aviation profession. At the same time, advances in automation and ergonomics, human factors research, and new conceptions of air traffic control for the national airspace call for more sophisticated applications and knowledge of Aviation English.

In our preoccupation with political upheaval and the application of new technologies, we need to be reminded that the use of English in aviation, both in flight and non-flight areas, continues to present a serious challenge for students preparing to enter the industry as well as for many practicing professionals on a daily basis. This may not be considered business as usual, for appropriate and accurate language use cannot be taken for granted. Where there is a zero-tolerance level for error, there is a clear need for special knowledge and treatment.

AVIATION ENGLISH: WHAT IS IT?

When most of us think about specialized language associated with aviation, we tend to visualize pilots sitting in a cockpit communicating with air traffic controllers who follow a set of standard procedures to maintain order in the sky. There is more to the use of Aviation English, however.

The range of types of language uses in aviation is as great as in any human endeavor that involves the full range of human emotions, physical skills, and complex technical knowledge. Aviation gets more attention than many other fields, however, because of the safety issues that are self-apparent in flight and present, but less exposed, in aircraft maintenance: people can die from failures to use language appropriately and accurately.

These are the different content areas that are readily identified under the umbrella of Aviation English use:

1. Flight

Air Traffic Control

Flight Services

2. Technology

Airframe and Powerplant Mechanics

Avionics

Aircraft Manufacture
Flight Line Operations

3. Engineering

Aeronautical Engineering

Aerospace Engineering

4. Business

Airline/Charter Services

Fixed Based Operations

Airport Management

Marketing

5. Education/Training

Flight

Maintenance

Engineering

Business Administration

Simply naming the content focus of Aviation English, however, raises more questions than answers about what it is and how it works. To analyze and understand language use fully, it is necessary to focus on the total behavior and environment of making and sharing meaning. The question of what Aviation English is can only be answered by going beyond content to situation to consider who is using the language, what activities are unfolding in which language plays a key role, and what purpose the language use is serving. This leads to the concept of register.

\section{REGISTER AND RESTRICTED REGISTER}

Any variety of language that is identified with particular people who employ it in a particular way in particular situations is likely to qualify as a register. Examples would include the language of medicine or the hotel industry, and the subject of this paper, Aviation English. But we need to take this concept further and consider a more specialized subset of language use, namely, the restricted register of language use.

A good way to understand what is meant by a restricted register is to reflect on the relation between situation and language. We take for granted just how effectively we make inferences from language to situation about meaning. Just from hearing part of a spoken exchange we can often infer who is involved and what is going on: for example, by listening to the words of a pastor, bride, and groom. Similarly, we can make inferences from situation to language on the basis of observing what is going on and who is involved. When a 
basketball team huddles around its coach during a timeout after giving up five easy baskets in a row to their opponents, we have some notion of the gist of the coach's message to his players. Inferences are most easily made when spoken language operates in an instrumental manner in interpersonal contexts, although it applies equally to written texts that are situationally dependent.

This sense of language and situation awareness grows more keen as language and situation become more specific. This is the case with restricted registers. The more unique or specialized the situation and the language are, the easier it becomes for us to relate them, provided we have experience with the situation and its attendant use of language. Lacking such experience, however, we are likely to find it very difficult to relate situation and language use.

\section{TOWER COMMUNICATIONS:}

\section{AN EXAMPLE OF A RESTRICTED REGISTER}

Tower communications, that is, language communication between pilot and air traffic controller, is the restricted register most commonly associated with Aviation English, and, for obvious reasons, receives the most attention. It is an excellent example of how situation drives language use, of how they are inseparable in a restricted register. Flight crews and air traffic controllers routinely speak air traffic control English to direct, inform, question, and respond to each other regarding aircraft takeoff, flight, and landing. The following excerpts, identified by the time of transmission in parentheses, come from an exchange of spoken text that shows this kind of specialized, situation-dependent language use (NTSB, 1991, p. 144):

(2130:32) "Avianca 052 climb and maintain 3000."

(2130:36) "Negative sir we just running out of fuel we okay ... three thousand now okay."

Even without any aviation experience, a person reading or listening to this exchange could no doubt deduce that this is a pilot conversing with an air traffic controller, but might not be able to say much more about it. Experienced pilots or air traffic controllers, on the other hand, would have no difficulty in determining who is speaking and what is going on. Moreover, they might even recognize that the quotations have been taken from the ATC transcript of the aircraft accident report of Avianca Airlines flight 052, which crashed on Long Island, New York, in 1990, and know that the National Transportation Safety Board concluded that problems with limited English proficiency contributed to the causes of this terrible disaster.

A restricted register, then, is a very specialized, welldemarcated, and identifiable use of language, communicated in a spoken, written, or combined mode. The demands that such a use of language place on the first-time user or learner can be great indeed, especially for a person with limited English proficiency, and, in times of stress, even for the native speaker. Even pilots who are native English speakers have difficulty with the process of learning the language of tower communications. Learning to fly is an energy-draining emotional experience. The last thing that new pilots with 10 to 20 hours of flight time want to do is to carry on a dialogue with some stranger making demands on them. For a non-native speaker of English, the experience is certainly more daunting. The difficulties are clear from a linguistic point of view: a successful user of this restricted register must be able to comprehend and produce utterances that meet the specific language requirements of a very specific situation.

\section{TWO IMPORTANT FEATURES}

\section{OF RESTRICTED REGISTERS}

Register may be defined as a variety of language differentiated according to use. Restricted register may be defined as a specialized variety of idiosyncratic language use offering a narrow range of options to the user and showing a high degree of predictability in use. These definitions point to the importance of understanding the roles of idiosyncracy and probability in a restricted register. All restricted and specialized uses of language such as tower communications are idiosyncratic. They are limited and specialized in their wording; that is, their vocabulary and structure. There are fewer choices among words, and their combinations are equally limited as well. Each type of restricted register is unlike another because each is so closely allied to a particular situation and the activity in which language plays a role.

A second characteristic of a restricted use of language 
is that it is very predictable. Because there are few options in terms of the content, the way the language is exchanged, and the way in which it is organized, the probability is very high that certain words will occur with certain other words in certain structures at particular points in the language use. This language use is directly associated with the activity that is simultaneously going on.

Given the importance of the use to which language is put, it is useful at this point to reconsider the adequacy of a list such as that shown above, Aviation English content areas. Although it is helpful to list the numerous restricted registers covered by the umbrella term of Aviation English according to their content or activity focus, an analysis of only the content conveyed by language is not sufficient to characterize the relation between language and its use in a given situation. Situational language use also involves exchange and organization.

\section{WHAT IT MEANS}

\section{TO KNOW AND USE A LANGUAGE}

Language use is only possible when the users share the same system of meaning. Successful language users have to be able to comprehend and produce wording, that is, a correct and appropriate combination of vocabulary and grammar. To do this, however, they need to know much more than the content of the field of activity in which they are using language. This is true for both general and restricted uses of English and is the reason why a functional perspective of language is most helpful in describing and applying registers of language. We can practically view language use as being made up of three areas of meaning: content, exchange, and organization (Halliday, 1994).

Content generally refers to the wording that communicates the participants (who and what is involved in the use of language), the action or process (what is going on), and the circumstances (includes features such as where and how the action is taking place). For example, the content of the restricted register of tower communications refers to the referential language of air traffic control phraseology in use between pilot and controller.

There is also an exchange of meaning in the particular situations of language use. This refers to how meaning is exchanged with regard to information and "goods and services." Information is generally exchanged through the use of statements and questions, which give and request information. Goods and services are verbally exchanged by the use of offers and commands, that is, offers and requests for the doing of actions -- for something to happen. The exchange of meaning depends on many aspects of the situation in which the language is being used. One important aspect is the relationship between the language users. For example, the fact that one language user in an aircraft cockpit is the first officer and the other is the second officer will affect the wording of their questions, offers, commands, and statements to each other.

The language user also needs control over the organization of the wording, to be able to combine wording into logically meaningful and connected pieces of language use. An example would be following an appropriate verbal sequence to obtain a flight clearance, or using a pre-flight checklist.

Content, exchange, and organization, then, are all parts of shared meaning and equally important in learning and using language. Moreover, they are interwoven and must occur together during language comprehension (listening or reading) and during language production (writing or speaking) if language use is to be successful.

The would-be users of the register of tower communications, controller or pilot, ideally prepare through initial conceptual training combining the learning of language (content, exchange, and organization) and technical skills. The learner's ability to deploy appropriate language progresses most quickly when accompanied by hands-on experience, going from simulation to real experience flying an aircraft individually or as a member of a flight crew, or controlling aircraft in a control tower. This is how language is situationally learned, combining content, exchange, and organization of meaning with training in the activity demanded by the situation.

TOWER COMMUNICATIONS:

AN EXAMPLE OF KNOWING AND USING A RESTRICTED REGISTER 
Let's briefly analyze just the wording in the exchange given above in terms of content, exchange, and organization. This is an exchange between an air traffic controller and the second officer of Avianca Airlines Flight 052 on January 25, 1990 (NTSB, 1991, p. 144):

(2130:32) "Avianca 052 climb and maintain 3000." (2130:36) "Negative sir we just running out of fuel we okay ... three thousand now okay."

In the first transmission, "Avianca 052 climb and maintain 3000," there are content references to what is involved (the aircraft "Avianca fifty two"), to what is going on (the actions of "climb" and "maintain"), and to the circumstances (the location of "three thousand" feet). In the second transmission, "Negative sir we just running out of fuel we okay three thousand now okay," there are references to who and what are involved (the "sir," "we," and the "fuel"), to what is going on (the action of "running out of"), and to the circumstances of manner ("okay") and of location ("three thousand" feet).

As for the exchange of information and/or goods and services by asking, stating, requesting, and commanding in the first transmission, there are two commands given by the controller: "climb and maintain." In the response from the second officer, there are the statements "Negative we just running out of fuel," and "we okay three thousand now okay." The polite and deferential uses of "sir" and "just" are striking and important indicators of relationship.

The third area of language involves the organization of language into a recognizable type of text, in terms of sequence and parts. The identifying "Avianca 052" followed by a command, and the responding statement "Negative" show the logical sequence and relationship of identification, command, and response that is common and standard to tower communications.

Further analyses can be made to highlight the idiosyncratic features of this restricted register. The unique grammar of tower communications is one of these features and is apparent in this excerpt and the full cockpit voice recorder transcript. The patterns with which such features occur are readily identified and classified by systematically looking at extended samples of language use in large databases of authentic text.

A functional perspective on language allows for language use to be related to the situation in which it is found. Relating language and situation benefits from the cooperation of language and aviation professionals in areas such as joint investigations of safety concerns involving the use of language under stress and its contextdependency; of the interplay between standard ATC phraseology and general English and of prescribed and observed, or actual, language use; of the level and adequacy of the English used by non-native speakers of English in flight communications; and of the compliance of observed language use with national and international air traffic control procedures and standards.

\section{SOME RECOMMENDED READINGS}

\section{ON AVIATION ENGLISH}

What do we know about Aviation English? Undoubtedly a lot more than we have written down, and of what is written down, little we can readily access. There are remarkably few direct studies of this language register published in the language literature and few published materials focusing solely on language teaching. Much of the most practical, situation-based teaching materials is proprietary. This section describes a selection of available and useful readings that do study Aviation English directly in relation to the situations in which it is used. Most but not all of it focuses on tower communications.

As for proprietary materials, ongoing work at EmbryRiddle Aeronautical University is illustrative. An introductory course in flight communications is offered to students with limited English proficiency, and language labs supplement basic flight courses for students with perceived language deficiencies. The Embry-Riddle Language Institute provides a variety of English language courses for the aviation industry, including a series on English for Pilots and Air Traffic Control, and, in cooperation with other university departments, is developing specialized testing of air traffic control English.

Published materials on communication problems and their solutions include Steven Cushing's thoughtful and comprehensive studies of language factors in aviation with special reference to air-ground verbal communication. Many of his papers and reports, such as 
"Language and Communication-Related Problems of Aviation Safety" (Cushing, 1988), "Social/Cognitive Mismatch as a Source of Fatal Language Errors" (Cushing, 1991), and his co-authored "An Error-Resistant Linguistic Protocol for Air Traffic Control" (Cushing et al., 1989) explore social and cognitive aspects of language use and the possibilities for intelligent voice interface systems. His book Fatal Words (1994) is divided into sections on language-based communication problems, such as ambiguity and uncertain reference, on communication problems not based on language, such as problems with radios and compliance, and on potential solutions, including an intelligent voice interface for aviation communication.

A number of analyses have been written about the text of Aviation English, notably of the language of air traffic control. Frick and Sumby (1952) wrote a useful analysis, "Control Tower Language," which studied uncertainty and unpredictability in situation-dependent messages. They investigated the increased redundancy typical of special languages in relation to situational constraints and noted that although such a system is inefficient in terms of information transmission, redundancy effectively combats noise and error.

Other significant works providing analyses of tower communications include two that closely relate language and situation. Sumby's "The Control-Tower Language: A Case Study of a Specialized Language in Action" (1960) is a functional analysis of ATC wording, relating language use and situation. In 1987, Vatnsdal wrote more extensively on "Register Analysis: The Language of Air Traffic Control." He based his analysis on five transcripts of automatic, continuous tape recording of control tower/pilot transactions at Edinburgh Airport in Scotland. This is a very detailed work, covering analysis of content units, discourse framework, vocabulary, information structure, and grammar from a systemicfunctional perspective. He uses the concept of register as the basis of an analysis of ATC as discourse.

Vatnsdal's analytical framework deserves closer scrutiny in this introduction to Aviation English. His content units describe the content wording of what he lists as $\mathbf{2 0}$ obligatory units, such as aircraft identification, ground station identification, clearance, approach, runway, and one optional unit -- politeness. He characterizes the four variables of field, mode, role, and formality, and provides a useful discourse framework of acts, moves, and exchanges in terms of mini-situations. Examples of acts include the call, the request, the check, the directive, and the informative; examples of moves include opening, answering, and followup; examples of exchange include initiation, response, and feedback. There are sections on vocabulary as part of the content function, lexical density, the proportional occurrence of lexical, or content, items in relation to the total number of words, and information structure, the organization of information as given and new. For example, in the case of the spoken "you are cleared," the obligatory new lexical element selected is "cleared," while the optional given, or understood, element, "you," is frequently omitted.

Vatnsdal's section on grammar fully expands on the significance of idiosyncratic language use in this restricted register, showing how little information can be drawn from the text alone in this case, since it is so dependent on the communicators' contextual knowledge of situational factors. Language use is characterized by disjunctive and abbreviated wording, with an extensive use of ellipsis, or the leaving out of single words and phrases from the text, such as in "I need you ten," assuming that the listener will understand this as "I need you to fly ten mile legs in the holding pattern." The wording is exophoric, that is, it refers to many objects, events, places, and people not directly mentioned in the text, yet which are still known to the communicators. He shows how the cohesion, or logical connections between text parts normally found in general English, are lacking in this register, with the result that the language use appears cryptic and clipped.

Other articles compare general English and restricted registers or apply cognitive constructs to the language used. In "Natural Language vs. Purpose-Built Languages," Varantola (1989) discusses English as a fixed language serving as a communication medium in air traffic control (airspeak) and maritime navigation (seaspeak) with special attention to the relationship between natural and special codes and the correlation of the functions of clarity and brevity. Philps' "Linguistic Security in the Syntactic Structures of Air Traffic Control English" 
(1991) is a comparison of the syntax of "natural English" and the "sublanguage" of pilot/controller communications with reference to the Tenerife air disaster and controller communication guidelines. Delibo writes about genre, or text-type, and the cognitive constructs of schema and script in "The Discourse of Specialty and the Schema Components" (1991). This analyzes a pilot/controller interchange and shows how the pilot's communication errors occasion non-standard turns by the controller.

In the area of language teaching, Hirayama-Grant and Sedgwick have written on "ESP Syllabus Design Processes in Retrospect" (1978) for ATC study materials. This paper is part of a collection of accounts of the development of ESP materials using careful analysis of the linguistic and discoursal features of the language of interest. Ragan has written about the use of a functional approach to language teaching: (a) on the relation of general English to specialist English, such as the restricted registers of Aviation English in "A Functional Approach to Subject Specialism in Teaching ESP ${ }^{n}$ (1994a); (b) on teaching students with limited English proficiency about Aviation English in "Aeronautical English: Research and Applications" (1993) and "Subject Specialism and General English in Aviation ESP" (1994b); and (c) on the general utility of a functional approach to teaching English language use in "Functions and Communicative Language Teaching" (1991).

McCann and Teasdale, in "Eurocontrol Standard Testing Project: Exit Test in English for Air Traffic Control" (1992), describe a test development project for air traffic control trainees under the management of the British Council. The test itself has been published by the Institute of Air Navigation Services (1994).

The study of meaning, or semantics, gets attention from Hullen in his 1981 article "Movements on Earth and in the Air: A Study of Certain Verbs." Hullen describes the lexical and semantic distinctions between ordinary and special language in aviation. He refers to the indexicality of special language -- its ability to express particular features of the world that it is not necessary to express in the context of ordinary language. This relies on both the creation of technical terminology and the redefinition of ordinary language.

In "Linguistic Methodology for the Analysis of
Aviation Accidents" (1983) and "Crew Communications as a Factor in Aviation Accidents" (1986), Goguen and Linde connect discourse analysis to the investigation of aviation safety needs. Linde applies this approach in "The Quantitative Study of Communicative Success: Politeness and Accidents in Aviation Discourse" (1988), which makes use of sociolinguistic analysis and serves as a model of applied linguistics responding to aviation language needs. This study correlates mitigation, or politeness, in statements among flight crew members taken from NTSB Aircraft Accident Reports with realworld variables such as (a) action initiated in response to an utterance at a particular level of politeness, (b) absence of response, (c) verbal response, or (d) a verbal response in conjunction with data suggesting initiation of action. She also distinguishes between a topic failed speech act, defined as "any speech acts expressing a new topic not followed by a speech act having the same topic from another speaker" (Linde, 1988, p. 389), and an unratified draft order. The latter is a suggestion that is acknowledged by the captain but refused as irrelevant to the situation at hand.

Linde hypothesizes that (a) requests to superiors are more mitigated than requests to subordinates; (b) requests are less mitigated in problem flight conditions than in normal cruise conditions; (c) unratified draft orders, or suggestions by a subordinate, are more mitigated than ratified draft orders; and (d) topic failed speech acts generally tend to be more mitigated than speech acts that succeed in introducing their topic.

Human factors research largely investigates the air traffic control system in terms of its capabilities and limitations, often exploring human error and systeminduced human error. The focus on language follows a psychological and technological perspective on information processing including properties of controller and pilot messages, the communication medium, and the ATC communication task of interest.

A number of relevant articles are cited here to serve as a way into language-related human factors research. Fowler (1980) analyzes specific examples of crashes and near midair collisions to identify existing and potential human error and system-induced human errors in his article on "Air Traffic Control Problems: A Pilot's View." 
In an interesting field study of 12 hours of pilot/controller communication titled "Analysis of Problems in Routine Controller-Pilot Communication," Morrow, Lee, and Rodvald (1993) present a framework describing how controllers and pilots successfully communicate, which they use to define factors that might lead to communication problems. They specifically address procedural deviations and inaccuracies, and apply Goguen and Linde's conception of speech acts to an ATC environment. Other research addresses informationprocessing parameters such as time required for transmission of time-critical air traffic control messages (Cardosi, 1993), effects of noise exposure (Robertson \& Williams, 1975), short-term memory factors (Loftus, 1979), synthesized speech rate and pitch effects (Simpson \& Marchionda-Frost, 1984), and speech intelligibility under conditions of active jamming (Nixson, McKinley, \& Moore, 1982) and as affected by communication headsets (Townsend, 1978).

\section{AVIATION ENGLISH: THE FUTURE}

There is a need for us to know more about the various areas of Aviation English, including areas that receive less attention than ATC but are critical as well, such as pilot/crew and pilot/co-pilot exchanges and non-flight uses of language such as those occurring during aircraft maintenance. We need to do a better job of sharing what we collectively know already as well as to investigate what remains unclear to meet future needs. Many of the authors cited above have made useful suggestions that point the way. It is easy to agree with Linde, who suggests that the quantitative study of communicative effectiveness is "a possible and necessary direction for discourse analysis" (1988, p. 397). There is no such study for the restricted register of ATC.

Hirayama-Grant and Sedgwick recognize "a pressing need for a different and more powerful analytical framework for handling language variation on which to base teaching materials" (1978, p. 323). This framework is found in the pioneering work of Vatsndal. Based on the concept of register, it provides the sort of broad yet specific analysis of linguistic and discoursal features necessary to understand a restricted register such as the language of the air.

We should note that Vatnsdal indicates that his "data was all obtained from the same source, it was checked against the relevant parts of a textbook example." He found that it "showed few marked differences from the authentic examples" (1987, p. 47). However, this disagrees with our findings at Embry-Riddle Aeronautical University of the nature of authentic ground-air communications, based on analyses of sources such as the Aircraft Accident Report of the flight of Avianca 052. It is clear that extensive discrepancies exist between proper, textbook ATC phraseology and authentic language use. These are the procedural deviations and inaccuracies reported on by Morrow, Lee, and Rodvald (1993) and others. This is why Varantola (1989) believes that the question of how much general language is needed for special-purpose communication should be addressed.

A better description is needed of the international use of the language of the air, one that is based on a qualitative and quantitative analysis of prescribed and actual language use. Indeed, the National Transportation Safety Board indicated in the Aircraft Accident Report for the Avianca flight 052 discussed above that "there is a need for the FAA to review all official definitions of words and phrases used to describe minimum and emergency fuel" (1991, p. 65) and recommended the FAA:

Immediately notify all domestic and foreign air carriers to emphasize that all pilots operating commercial air transport flights in the United States (U.S.) National Airspace System (NAS) must be thoroughly knowledgeable of the flight operating and air traffic control (ATC) rules and procedures, including standard phraseology, for operating in the U.S. NAS (Class I, Urgent Action). (1991, p. 77)

This recommendation grew out of their conclusion that "intracockpit conversations indicate a total breakdown in communications by the flightcrew in its attempts to relay the situation to ATC" (NTSB, 1991, p. 58) and that "much of the flightcrew's failure to communicate effectively resulted from limitations in their ability to use the English language, and in their knowledge of standard ATC terminology" (NTSB, 1991, p. 58). Indeed, in some of the testimony given during the 
hearings leading up to the report, one non-native English-speaking captain warned that many of the nonU.S. airline pilots have " 200 word vocabularies" and are trusting the adequacy of this knowledge to allow them to operate safely in the United States (NTSB, 1991, p. 63).

From a safety point of view -- for both pilots and passengers -- the actions called for by the National Transportation Safety Board are appreciated. However, from a linguistic, training, and research point of view, this drop-in-the-bucket approach' to the overall communication problem simply illustrates how difficult it is for aviation professionals to understand the magnitude of the situation or of the nature of language use. What is called for is more systematic knowledge about Aviation English in response to the needs of students and professionals, both native and non-native speakers of English.

\section{MEETING THE NEEDS OF USERS OF AVIATION ENGLISH}

There are many needs to be met. Even native Englishspeaking students -- especially American students coming out of high schools less prepared verbally and mathematically for the challenges of any academic pursuit -- need some sort of support to help them become more proficient with language. The problem for individuals with limited English proficiency entering and already working in aviation is more acute. These people need more exposure to systematic language study as part of the situational, content- and skill-oriented training that is the norm in the aviation profession. Regulatory and licensing agencies must provide the direction and the motivation for such instruction. Research in Aviation English will help identify features that need attention in the different areas of interest, such as a comparison of prescribed and actual language use for the restricted register of ATC. Documentation of discrepancies in this case could lead to recommendations regarding the setting of standards and associated testing devices and evaluation. Standardization, in turn, will form the basis for creating the kinds of curricula necessary for students and professionals alike to improve their use of Aviation English at the same time that they learn and improve their professional skills and knowledge.

THE AVIATION ENGLISH CORPUS PROJECT
There has been a growing awareness by industry and government of the potential applications of large-scale, computerized databases of language called corpora. The collection of large samples of spoken and written English begun in the 1960s has led to a corpus data explosion of third-generation corpora "measured in the hundreds of millions of words, almost all in commercial hands, exploiting the technologies of computer text processing" (Leech, 1991, p. 10) and exemplified by the monitor corpus of the Birmingham Collection English (Sinclair, 1991). The Linguistic Data Consortium of the University of Pennsylvania (Linguistic Data Consortium, 1996) provides members and non-members a broad range of corpora ranging from Mandarin Chinese Newspaper Text to United Nations Parallel Text in English, French, and Spanish. They also have an Air Traffic Control corpus available on eight CD-ROMS of nearly 70 hours of recorded conversations between controllers and pilots in three sub-corpora collected at Dallas-Fort Worth International Airport in Texas, Logan International Airport in Boston, Massachusetts, and the Washington National Airport in Arlington, Virginia. The data were collected by Texas Instruments under contract with DARPA for the purpose of investigating the ATC system as a speech recognition application.

A pilot project is under way at Embry-Riddle Aeronautical University to investigate corpora of selected areas of Aviation English. The initial area of interest is the study of tower communications. Following accepted guidelines and established principles in the field of corpus linguistics (Sinclair, 1991), this project calls for spoken and written text to be collected, stored, and processed by computer. The corpus should ultimately comprise bodies of both prescribed and natural, or authentic, language use and be available for a variety of research purposes. Only larger amounts of such data in the tens of millions of words will lead to reliable descriptive statements of language use. This is the wedding of quantitative and qualitative research alluded to above.

Such a pilot project involves these key steps:

1. Collection: Obtaining a sizable number of hours of recordings of controller/pilot and flight crew communications representative of the types of exchanges 
of interest.

2. Preparation: Transcribing, keyboarding, and scanning recordings into computer files.

3. Processing: Analyzing and marking computer file data with reference to selected linguistic and discoursal features most relevant to the language of the air.

4. Description: Describing the range of language behavior according to selected classification schemes, such as referential meaning and its context (for example, taxiing and takeoff procedures). '

5. Recommendation: Making recommendations about language use for the development of training materials, review by governing and regulatory bodies, creation of standardized testing instruments, refined applications in automated language recognition and generation, and improved machine/human interfaces.

\section{CONCLUSION}

This paper has introduced the concept and nature of Aviation English with particular reference to the restricted register of the language of tower communications. It has reviewed the content of readings selected to provide a sense of what we know and need to know about this use of language. Finally, it has promoted a project for the development and analysis of an Aviation English corpus.

Stories of miscommunication abound in a profession like aviation, where communication is critical and English is at risk. This paper concludes with an anecdote about a student pilot with limited English proficiency who was asking the tower for permission to enter the traffic pattern to make a landing. The controller could not fully understand what he wanted, so he asked the student to state his intentions. The student responded by saying, "I intend to become a private pilot." The collective intention of all aviation professionals involved with the use of Aviation English should be even more clear: to learn more about it, and to improve and promote a common understanding of its use. $\square$

Peter H. Ragan earned a Ph.D. in English Language at the National University of Singapore, his master's degree in English as a Second Language at the University of Hawaii, and his bachelor's degree in Psychology at the University of California, Berkeley. He is an associate professor and director of International English with the Department of Humanities and Social Sciences at Embry-Riddle Aeronautical University.

\section{REFERENCES}

Cardosi, K. M. (1993). Time required for transmission of time-critical air traffic control messages in an enroute environment. International Journal of Aviation Psychology, 3(4), 303-313.

Cushing, S. (1988). Language and communication-related problems of aviation safety. Washington, DC: U.S. Department of Education. (ERIC Document Reproduction Service No. ED 296 595, FL 017 504.)

Cushing, S. (1991). Social/cognitive mismatch as a source of fatal language errors: Implications for standardization. Proceedings, Fourth International Aviation English Forum: Aviation English Standards. Paris.

Cushing, S. (1994). Fatal words. Chicago: University of Chicago Press.

Cushing, S., Artemieff, S., Elkin, G., Paine, B., Willard, S., Sisco, A., \& Ross, D. (1989). An error-resistant linguistic protocol for air traffic control. (NASA Contractor Report NAG 2-564.) Mountain View, CA: NASA Ames Research Center.

Delibo, J. A. (1991). The discourse of speciality and the schema components. The ESPecialist, 12(1-2), 41-58.

Fowler, F. (1980). Air traffic control problems: A pilot's view. Human Factors, 22(6), 645-653. 
Frick, F., \& Sumby, W. (1952). Control tower language. Journal of the Acoustical Society of America, 24(6), 595-596. Goguen, J., \& Linde, C. (1983). Linguistic methodology for the analysis of aviation accidents. (NASA Contractor Report 88254.) Moffett Field, CA: NASA Ames Research Center.

Goguen, J., \& Linde, C. (1986). Crew communications as a factor in aviation accidents. (NASA Contractor Report 3741.) Moffett Field, CA: NASA Ames Research Center.

Halliday, M. (1994). An introduction to functional grammar. London: Arnold.

Hirayama-Grant, G., \& Sedgwick, M. (1978). ESP syllabus design processes in retrospect. In M. T. Trimble, L. Trimble, \& K. Drobnic (Eds.), English for specific purposes: Science and technology (pp. 322-336). Corvallis, OR: English Language Institute, Oregon State University.

Hullen, W. (1981). Movements on eárth and in the air: A study of certain verbs. The ESP Journal, 1(21), 141-153.

Institute of Air Navigation Services. (1994). English language exit test for student air traffic controllers. Eurocontrol Institute of Air Navigation Services, Luxembourg.

Leech, G. (1991). The state of the art in corpus linguistics. In K. Aijmer \& B. Altenberg (Eds.), English corpus linguistics (pp. 8-29). New York: Longman.

Linde, C. (1988). The quantitative study of communicative success: Politeness and accidents in aviation discourse. Language in Society, 17(3), 375-399.

Linguistic Data Consortium. (1996). Air traffic control corpus. Available World Wide Web: http://www.ldc.upenn.edu...me_files/atc.readme.html.

Loftus, G. R. (1979). Short-term memory factors in ground controller/pilot communication. Human Factors, 21(2), 169181.

McCann, P., \& Teasdale, A (1992, Autumn). Eurocontrol standard testing project: Exit test in English for air traffic control. Language testing update, 12.

Morrow, D., Lee, A., \& Rodvald, M. (1993). Analysis of problems in routine controller-pilot communication. International Journal of Aviation Psychology, 3(4), 285-302.

National Transportation Safety Board. (1991). Aircraft accident report. Avianca, the airline of Columbia, Boeing $707-$ 321B, HK 2016, Fuel exhaustion, Cove Neck, New York, January 25, 1990. NTSB/AAR-91/04.

Nixson, C. W., McKinley, R. L., \& Moore, T. J. (1982). Increase in jammed word intelligibility due to training of listeners. Aviation, Space, and Environmental Medicine, 53(3), 717-724.

Notice of proposed rulemaking (NPRM 95-11). (1995, August 11). Federal Register. Washington, DC: U.S. Government Printing Office.

Pena to airlines: Elevate safety margins. (1995, January 16). Air Transport, 26.

Philps, D. (1991). Linguistic security in the syntactic structures of air traffic control English. English World-Wide, 12(1), 103-124.

Ragan, P. (1991). Functions and communicative language teaching. Occasional Papers in Systemic Linguistics, 5, 143-158.

Ragan, P. (1993, April). Aeronautical English: Research and applications. Paper presented at the 27th International TESOL Conference, Atlanta, GA.

Ragan, P. (1994a, August). A functional approach to subject specialism in teaching ESP. Paper presented at the 21st International Systemic-Functional Conference, Ghent, Belgium.

Ragan, P. (1994b). Subject specialism and general English in aviation ESP. TESOL Matters, 4(4), 7.

Robertson, R. M., \& Williams, C. E. (1975, May). Effect of noise exposure during primary flight training on the conventional and high-frequency hearing of student pilots. Aviation, Space, and Environmental Medicine, 46(5), 717. 724.

Simpson, C. A, and Marchionda-Frost, K. (1984). Synthesized speech rate and pitch effects on intelligibility of warning messages for pilots. Human Factors, 26(5), 509-517. 
Sinclair, J. (1991). Corpus, concordance, collocation. Oxford: Oxford University Press.

Sumby, W. (1960). The control-tower language: A case study of a specialized language in action. Language and Speech, 3, 61-70.

Townsend, T. H. (1978). Speech intelligibility through communication headsets for general aviation. Aviation, Space, and Environmental Medicine, 49(3), 466-469.

Varantola, K. (1989). Natural language vs. purpose-built languages. Neuphilologische Mitteilungen, 90(2), 173-183.

Vatnsdal, A. O. (1987). Register analysis: The language of air traffic control. Occasional Papers in Systemic Linguistics, 1, 43-83. 